\title{
1 Selecting species for restoration in foundational
}

\section{2 assemblages}

4 Joshua S. Madin ${ }^{1 *}$, Michael McWilliam¹, Kate Quigley², Line K. Bay², David Bellwood ${ }^{3}$, 5 Christopher Doropoulos ${ }^{4}$, Leanne Fernandes ${ }^{5}$, Peter Harrison ${ }^{6}$, Andrew S. Hoey ${ }^{3}$, Peter J.

6 Mumby $^{7}$, Zoe T. Richards ${ }^{8}$, Cynthia Riginos ${ }^{7}$, David J. Suggett ${ }^{9}$, Madeleine J. H. van Oppen ${ }^{2,10}$

1. Hawai $\square$ i Institute of Marine Biology, University of Hawai $\square$ i at Manoa, Kāne'ohe, Hawai $\square$ i, $9 \quad$ USA

10 2. Australian Institute of Marine Science, Townsville, Queensland, Australia

11 3. ARC Centre of Excellence for Coral Reef Studies, James Cook University, Townsville, 12 Queensland, Australia

13 4. CSIRO Oceans \& Atmosphere, Brisbane, Queensland, Australia

14 5. Great Barrier Reef Marine Park Authority, Townsville, Queensland, Australia

15 6. Marine Ecology Research Centre at Southern Cross University, New South Wales, Australia

16 7. School of Biological Sciences, The University of Queensland, St. Lucia, Queensland, 17 Australia

18 8. Coral Conservation and Research Group, Trace and Environmental DNA Laboratory, School 19 of Molecular and Life Sciences, Curtin University, Bentley, Western Australia, Australia

20 9. University of Technology Sydney, Climate Change Cluster, Sydney, New South Wales, $21 \quad$ Australia

22 10. School of BioSciences, The University of Melbourne, Parkville, Victoria, Australia

24 *jmadin@hawaii.edu 


\section{Abstract}

1. Humans have long sought to restore species but little attention has been directed at how best to do so for rich assemblages of foundation species that support ecosystems, like rainforests and coral reefs that are increasingly threatened by environmental change.

2. We developed a two-part triage process for selecting optimized sets of species for restoration. We demonstrated this process using phenotypic traits and ecological characteristics for reef building corals found along the east coast of Australia. Without clear linkages between phenotypic traits and ecosystem functions, the first part of the triage hedges against function loss by ensuring an even spread of life history traits. The second part hedges against future species losses by weighting species based on characteristics that are known to increase their ecological persistence to current environmental pressures-abundance, species range and thermal bleaching toleranceas well as their amenability to restoration methods.

3. We identified sets of ecologically persistent and restorable species most likely to protect against functional loss by examining marginal returns in occupancy of phenotypic trait space per restored species.

4. We also compared sets of species with those from the southern-most accretional reef as well as a coral restoration program to demonstrate how trait space occupancy is likely to protect against local loss of ecosystem function.

5. Synthesis and applications. A quantitative approach to selecting sets of foundational species for restoration can inform decisions about ecosystem protection to guide and optimize future restoration efforts. The approach addresses the need to insure against unpredictable losses of ecosystem functions by investing in a wide range of phenotypes. Furthermore, the flexibility of the approach enables the functional goals of restoration to vary depending on environmental context, stakeholder values, and the spatial and

Keywords

55 Restoration; foundation species; triage; phenotypic traits; ecosystem function; hermatypic corals 


\section{Introduction}

58 The rate and extent of environmental change experienced by contemporary ecosystems have 59 resulted in major deviations from their historical state (Hobbs et al., 2011). Conservation alone 60 may therefore no longer suffice to preserve biodiversity and ecosystem functions, and restoration 61 is often considered a now required addition. The objective of ecosystem restoration is, through

62 human intervention, to recover a disturbed or degraded ecosystem as far as possible towards 63 some previous state. Interventions in the coastal and marine realm can be direct, such as 64 propagation and field deployment of habitat builders through seeds (e.g., seagrass in Virginia 65 Orth et al., 2020), propagules (e.g., oysters in South Australia - Vanderklift et al., 2020), early 66 recruits (e.g., kelp - Fredriksen et al., 2020; coral - Randall et al., 2020) or parts of adult tissues 67 (e.g., coral gardening - Rinkevich 2014). Indirect interventions, such as physical stabilization of 68 degraded reef structures are also possible (Ceccarelli et al., 2020).

70 To date, the augmentation or reintroduction of one or few species has been the most common 71 approach, such as the restoration of the endangered Caribbean coral species Acropora 72 cervicornis and A. palmata (Ladd et al., 2019), the reintroduction of the greater bilby in some 73 parts of Australia (Lott et al., 2020), the gray wolf across parts of Europe and North America 74 (Ripple et al 2014), and assisted colonization of the Tasmanian Devil to the Australian mainland 75 (Brainard 2020). However, climate change is now affecting many assemblages of foundation 76 species in most if not all the world's ecosystems - forests, kelp forest, and coral reefs-leading 77 to a necessary broadening of focus of restoration activities to encompass more species and their 78 contributions to ecosystem functioning (Brudvig \& Mabry 2008; Ladouceur \& Shackelford 79 2021).

81 Prioritizing sets of species for the restoration of biodiverse ecosystems is a challenging task, and 82 different approaches for decision making have been used. For instance, some approaches focus 83 on the roles that species play in providing particular ecosystem goods or services, including 84 carbon storage in rainforests (Strassburg et al., 2020) or mangrove forests (Adame et al., 2014), 85 or reef accretion on coral reefs for coastal protection (Bellwood et al., 2019). Another often used 86 focus is on keystone species: species that maintain the organization, stability, and function of 
87 their communities, and have disproportionately large, inimitable impacts on their ecosystems

88 (Hale et al., 2018). Alternatively, weedy pioneer species may quickly restore habitat functions

89 such as such as providing shelter or stabilizing substratum, such as the emphasis on fast growing

90 acroporids in coral gardening initiatives (Bostrom-Einarsson et al., 2020). However, the

91 objective selection of species based on defined ecological, functional and logistical criteria are

92 rare (Suding et al., 2004; Lamb 2018). Some examples exist for forest restoration (Meli et al.,

93 2013), and some have used linkages between phenotypic traits and ecosystem functions to select

94 species (Giannini et al., 2017; Rayome et al., 2019).

An overarching challenge is that restoration initiatives need to anticipate future ecosystem states

97 which are expected to be very different due to the escalating impacts of climate change (Rogers

98 et al., 2015; Gaitán $\square$ Espitia \& Hobday 2021). Faced with complex ecosystems, multiple threats

99 to biodiversity and limited funding, conservation practitioners must prioritize investment into

100 different management options, including restoration actions, and difficult decisions must be

101 made about which sets of species to allocate resources to (Game et al., 2018). Strategic decisions

102 must be taken about supporting those most likely to do better to improve future persistence and

103 resilience, and those that will struggle and potentially push them through a period of elevated and

104 prolonged stress; especially those that are already closer to their existing physiological limits,

105 like reef-building corals. Protecting habitat-forming species such as corals is imperative for

106 securing the ecological functions and socio-economic services they provide such as reef

107 building, habitat and food provisioning for commercially important species, primary production,

108 nutrient recycling, natural products, and social, cultural and recreational opportunities.

110 In this paper, we developed a two-part triage process for selecting sets of species for the 111 restoration or maintenance of foundational assemblages, for which we use reef-building corals as

112 an example. The first part centered on the restoration of ecosystem functions provided by 113 foundational assemblages, such as habitat engineering (Ellison et al., 2005) (Fig. 1). However, 114 rather than targeting specific ecosystem functions (Fig. 1a), we propose to minimize loss of 115 function by maximizing phenotypic variation (Fig. 1b) for several reasons. First, mechanistic 116 linkages between phenotypic traits of species and functions are poorly understood, especially for 117 coral reefs (Bellwood et al., 2019). Second, the species that support specific functions are likely 
118 to differ depending on the situation (e.g., disturbance history) and site-specific conditions. Third,

119 maximizing life history variation minimizes the risk of wholesale species loss, because no

120 species is at a selective optimum in all situations and environments (Stearns 1992). Fourth,

121 important ecosystem functions, such as habitat engineering and ecological succession, tend to be

122 supported by a broad range of life history combinations (e.g., builders, fillers and cementers

123 [Goreau 1963]; weedy, competitive and stress-tolerant [Darling et al., 2012]). Finally, a bet

124 hedging approach also acts to increase phylogenetic diversity because many life history traits are

125 evolutionarily conserved (Westoby et al., 2002).

127 The second part of the triage process is to select species based on characteristics that make them

128 better equipped to avoid depletion and resist or recover from large-scale events like fires or 129 marine heatwaves (Fig. 1c). For example, species with small range sizes and small local 130 populations generally have a higher extinction risk (Staude et al., 2020), while species with 131 higher local abundances tend to bounce back faster following disturbance (Halford et al., 2004).

132 Often there are synergistic relationships-for example, extinction risk tends to be greater for 133 geographically limited and locally rare species (double jeopardy; Brown 1984)—but not always 134 (Hughes et al., 2014). Meanwhile, some species are more tolerant to disturbances and gradual 135 changes that are expected to become more frequent or more intense in the future through rapid 136 adaptation. Suitability of species to restoration can also be considered as a characteristic of 137 ecological persistence; albeit one requiring human intervention (Suggett et al., 2019). For 138 example, restoration may be facilitated by the use of species that can be easily propagated in the 139 laboratory via sexual reproduction, grown in nurseries and outplanted, or manipulated in the field 140 (Rinkevich 2020; Randall et al., 2020). Furthermore, some phenotypic traits and ecological 141 characteristics make some species better candidates for restoration than others. For instance, it is 142 easier to generate coral fragments from branching species than from massive species, therefore 143 most restoration efforts on coral reefs have historically focused on branching corals (Bostrom144 Einarsson et al., 2020). Similarly, restoring local areas with species that have large geographical 145 ranges will improve connectivity (Hock et al., 2017).

147 The overall aim was to develop a quantitative approach to select a set of $n$ species for restoration, 148 recognizing that the goals of restoration can vary enormously across systems. The approach we 
149 developed aims to maximize the probability of maintaining phylogenetic diversity and ecosystem

150 function, and therefore protect against a range of sensitivities to future stressors. We demonstrate

151 this approach with reef building corals found on the east coast of Australia, including the Great

152 Barrier Reef, a region that has declined severely over the past few decades (De'ath et al., 2012;

153 Hughes et al., 2017). Here, coral reef restoration activities are already underway to address the

154 local-scale depletion of coral populations (Boström-Einarsson et al., 2020; Howlett et al., in

155 review) and larger scale restoration interventions are in the research and development phase

156 (Anthony et al. 2020). Although the data and results are only illustrative at this stage, and further

157 scrutiny is required before making formal restoration decisions at appropriate and manageable

158 scales (McAfee et al., 2021), it provides a quantitative, reproducible and adaptable basis for

159 selecting species for restoration projects and restoration research.

Materials and methods

163 Spectrum of life histories-The first part of the process required collation of quantitative 164 phenotypic traits for species that capture as many life history trade-offs as possible (Gallagher et 165 al., 2020), such as acquisition-conservation and propagule size-number (Westoby et al., 2002).

166 For our demonstration, we use a dataset for 396 species found along the east coast of Australia 167 from McWilliam et al. (2018) with the following traits: growth rate, corallite width, 168 rugosity/branch spacing, surface area per unit volume, colony height, maximum colony 169 size/diameter, and skeletal density. The trait data enabled us to capture important dimensions of 170 species life history, ranging from fast to slow growth (Darling et al., 2012), fragile to robust 171 morphologies (Zawada et al., 2019), and small to large colonies that drives up colony fecundity 172 (Alvarez-Noriega et al., 2016). The trait space was calculated using a principal components 173 analysis (PCA) of the seven traits and is presented in Fig. 2a for the 396 species.

175 We also viewed the trait space through the lens of one ecosystem function, reef building, by 176 adopting Goreau's (1963) classification of reef species into builders, fillers and cementers; an 177 approach that has been supported by modern synthesis (González-Barrios \& Alverez Filip 2018).

178 Within the McWilliam et al. (2018) trait space, builders were classified as species with the 179 highest values of size, height, and volume; fillers with largest values of size and rugosity; and 
cementers with the largest sizes and smallest height values (Fig. 2a, red vectors). Ecosystem functions such as reef building and habitat construction requires a broad range of life historiesranging from slow growing, potentially large builders (i.e., late successional species) to dense

183 skeleton, encrusting cementers to fast growing, morphological complex fillers (i.e., weedy or 184 early successional species). Other functions tend to require specific trait combinations (Fig. 2b).

185 For example, coral species with higher surface area to volume ratios, rugosities and growth rates 186 tend to generate habitat complexity that is reportedly important as fish habitats (Graham \& Nash 187 2013) and have a high value for human uses, such as tourism and recreation, because they are generally considered aesthetically appealing (Marshall et al., 2019).

While there are many definitions of phenotypic trait diversity (Villéger et al., 2008), our goal under a hedging strategy was to evenly capture the largest area of trait space with the fewest 192 species, and therefore to ensure a spread of species along important trait dimensions. This goal 193 was accomplished by iteratively removing the species closest to other species in the two194 dimensional area defined by PC1 and PC2 (which captured about 70\% total trait variation) until 195 a given number of species $n$ remained. Selection could also happen at higher dimensions to 196 capture higher levels of variation. We tried two approaches to measure the proximity of species 197 using R (R Core Team 2021): (1) the areas of Voronoi cells using the voronoi.mosaic function in 198 the tripack package (Renka et al., 2020), and (2) the nearest neighbor distances using the nndist 199 function in the spatstat package and only considering the single closest species (i.e., $k=1$; 200 Baddeley et al., 2015). Proximity values were normalized at each iteration by dividing by the 201 maximum distance or area, depending on the approach. A grid-based approach was used to 202 assess trait diversity throughout the study, whereby a grid of a given resolution was 203 superimposed onto the trait space (e.g., a 5 by 5 cell grid is shown in Fig. 3a and a 10 by 10 cell 204 grid in Fig. S2). Trait diversity was the proportion of possible grid cells with at least one species; 205 redundancy was the mean number of species in occupied possible grid cells.

207 Ecological persistence-For the second part of the triage process we focused on three 208 characteristics (ecological abundance, geographic range size and thermal bleaching 209 susceptibility) broadly defined as factors contributing to ecological persistence of reef building 210 coral species. We acknowledge that these characteristics will depend on current taxonomic 
211 designations that are currently being revised (Cowman et al., 2020). We used typical abundance

212 of species data from Veron (2000) and geographic distribution data from Hughes et al. (2013)

213 downloaded for the 396 species from the Coral Trait Database (Madin et al., 2016). Ecological

214 abundance was categorized by Veron (2000) as common, uncommon and rare, which we

215 normalized as 1, 0.5 and 0.25, respectively. Geographic extent was normalized by dividing the

216 range size of each species by the maximum range size for a species. Normalizing puts

217 characteristics on the same scale (i.e., between 0 and 1) (Fig. S1). Weightings can also be applied

218 to characteristics of ecological persistence to augment or diminish their importance, but we did

219 not do so here.

221 Thermal bleaching susceptibility is an increasingly relevant characteristic for coral ecological 222 persistence, but it is context dependent, highly variable, and poorly understood. Nonetheless, we 223 use the Coral Bleaching Index (BI) from Swain et al. (2016) to demonstrate how this variable 224 might be included in the triage analysis. BI is a value between 0 and 100, where higher values 225 correspond with more thermally vulnerable species. Therefore, we normalized BI by dividing by 226100 and subtracting the result from 1 (i.e., species with values closer to 1 are more resistant to 227 bleaching based on Swain et al. [2016]). BI values were available at the species level for 212 of 228 the species, and therefore genus level BIs were used for the remainder of the analysis in order to 229 retain all 396 species.

231 Restoration of reef corals is a relatively new field (Hein et al., 2021), and so there is little long232 term knowledge of what makes species more or less amenable to the restoration process. A meta233 analysis of coral restoration studies ranked the use of coral growth forms in restoration projects 234 (Boström-Einarsson et al., 2020). While this ranking likely reflects a historical focus on coral 235 gardening (i.e., fragmentation) as well as specific situations, such as the demise of branching 236 Acropora species in the Caribbean, we nonetheless utilize this ranking as an index of species 237 amenability to restoration. Species growth form was downloaded from the Coral Trait Database 238 and species were ranked from 1 to 6: columnar (1), tabular (2), encrusting (3), foliose (4), 239 massive (5), and branching (6), which includes corymbose and digitate. This ranking was 240 normalized by dividing values by six. 
242 Pairwise associations between PC1, PC2 and normalized ecological persistence variables for

243 species are shown in Fig. S1. Weighting species by characteristics was done by multiplying

244 normalized values. Species with values closer to $1-$ i.e., large ranges, common, and resistant to

245 bleaching-were considered ecologically persistent. To redirect focus of species selection to

246 vulnerable species, normalized variables were subtracted from 1 before proceeding. For example,

247 we also explored the triage process for species that were wide ranging and common, but

248 susceptible to bleaching.

250 Triage assessment-We compared triage results with two contrasting reef assemblages. The first

251 was the southern-most accretional reef assemblage along the east coast of Australia, Lord Howe

252 Island, built by approximately 50 coral species; however, we only include the 15 most common

253 species for our analysis, having greater than 5\% mean cover (Table S1). Contrasts were made by

254 comparing trait combinations in the Lord Howe assemblage with those generated by the triage

255 process with the same numbers of species $(n=15)$. The second set of species are those used for

256 out-planting for fragments by the Coral Nurture Program on the Great Barrier Reef throughout

257 the first two years of its planting activity across six northern GBR high value tourism reef sites

258 ( 20,000 out-plants; August 2018 - April 2020; Howlett et al., in review). The program is run by

259 tourism operators, and so tends to focus on abundant, fast growing branching species with

260 recognised aesthetic values to the tourism industry. Contrasts were made by comparing trait

261 combinations of the 39 Coral Nurture Program species with those generated by the triage process

262 for $n=39$ species.

\section{Results}

266 The nearest neighbor distance method produced the most even spread of species in the trait space

267 (Fig. 2c, points) because the Voronoi area method could not calculate areas for peripheral points

268 (Fig. 2c, crosses) that were inadvertently retained during the iterative species removal process.

270 Selecting species based solely on maximizing species spread in trait space (i.e., via nearest

271 neighbor distances) resulted in levels of occupancy in the trait space that were significantly

272 greater than random (Fig. 3a, yellow line sitting largely above the shaded 95\% confidence band). 
273 Conversely, selecting species based solely on ecological persistence led to both the lowest 274 occupancy in the trait space (i.e., spread of morphological and life history traits) and the highest 275 levels of redundancy (Figs. 3a and 3b green curves, respectively). These levels of occupancy and 276 redundancy were not significantly different to randomized species selection (black curves in 277 Figs. 3a and 3b, respectively, where the green "persistence" curves are captured by the shaded $27895 \%$ confidence bands). Selecting species based on both ecological persistence and trait diversity 279 resulted in some loss of trait diversity, but with levels of occupancy much greater than ecological 280 persistence alone (Fig. 3, red curves). Marginal returns in terms of occupancy per species was 281 high (approximately 5\% per species) for the combined triage scenario (i.e., red curve, Fig. 3a) up 282 until $n=11$ species, medium (approximately $2 \%$ per species) between from $n=11$ to $n=28$, and 283 low ( $<0.3 \%$ per species) above $n=28$. The general patterns shown in Fig. 3 were robust to the cell 284 size of the grid used to calculate occupancy (Fig. S2); with the proviso that more species are 285 required to maintain specified levels of occupancy and redundancy for finer grids. For example, 286 the region of medium marginal returns occurred between $n=29$ and $n=55$ for the 10 by 10 cell 287 grid (Fig. S2A, red curve). Based on marginal returns, the optimal number of species selected occurred somewhere between 29011 and 28. Fig. 4 shows triage values when selecting $n=20$ species at different stages of the 291 process for two scenarios: (1) considering ecologically persistent species (large geographic 292 range, ecologically abundant and resistant to bleaching) (Fig. 4a) and (2) considering large 293 geographic ranges and ecologically abundant species that are susceptible to bleaching (Fig. 4b).

294 While there is some overlap among the triage stages, Fig. 4 demonstrated how focal species can 295 change throughout the selection process. It also shows the selection outcomes of switching 296 species that are better ecologically, but are difficult to restore based on our criteria, while 297 simultaneously retaining an even spread of species in the trait space. Fig. $2 d$ contrasts triage for 29820 species with and without consideration of trait diversity, illustrating that, while cementers are 299 captured either way, because they tend to be ecologically persistent species, while builders and 300 fillers are not captured to the same extent if focused solely on ecological persistence 301 characteristics. 
303 The 15 species of Lord Howe Island assemblage showed lower trait diversity and higher

304 redundancy than would be produced by the triage process (Fig. 3, asterisks). Nonetheless, these

305 species occupied three highly distinctive trait combinations that largely overlap with the three

306 functional groups originally put forward by Goreau (1963) (Fig. 2e). The 39 species of the Coral

307 Nurture Program showed trait diversity markedly lower than expected by randomly selecting

308 species (Fig. 3a), resulting in high levels of redundancy (Fig. 3b). Indeed, the Lord Howe Island

309 assemblage showed similar levels of occupancy as the Coral Nurture Program with less than half

310 the species (Fig. 3a). Fig. 2f illustrates that these out-planted species are the fast growing, high

311 surface area to volume ratio species, with the exception of Galaxea fascicularis (Fig. 3e, red

312 arrow); they also only tend to capture Goreau's filler species category.

314 Discussion

316 The triage process developed here identified coral species for restoration projects based on both

317 ecologically beneficial characteristics and diversity of life history trait values. Selection based on

318 ecological persistence is important for hedging against future species loss, while phenotypic trait

319 diversity is important for hedging against both species loss and local ecosystem function loss.

320 The importance of individual species in ecosystem functions are poorly understood, particularly

321 for reef corals, and therefore our tactic was to prioritize an even spread of species across the trait

322 space rather than prioritizing particular phenotypic trait values or targeting regions in the trait

323 space (e.g., Fig. 2b). Even spread across the trait space (measured as gridded occupancy)

324 increased with the number of species selected; however, marginal returns declined at relatively

325 low numbers of species ( 20 species, Fig. 3a). However, this depended on the resolution at

326 which the trait space was gridded (Fig. S2). How finely spread species should be across trait

327 space for preserving particular ecosystem functions remains an open question. Meanwhile, the

328 number of species that can be selected for a restoration project will ultimately depend upon

329 project goals, as well as resource and logistical constraints. The flexible triage process developed

330 here can serve as a framework for such decisions.

332 The species lists shown in Fig. 4 is an illustration of outputs that include one potential planning 333 process, hence the anonymous labelling, as they are based on a relatively narrow set of 
334 ecological characteristic and phenotypic trait data. Future studies may build on our initial 335 analyses by including a broad range of traits (rather than primarily morphological traits presented 336 here) and imputing trait values for species with missing trait data (Fig. 1). For instance, certain 337 Acropora species are underrepresented in Fig. 4a due to their high bleaching sensitivity. We used 338 the colony growth form ranking by Bostrom-Einarsson et al. (2020) as the suitability for restoration trait. This trait is relevant for coral gardening approaches that fragment, grow and

340 then out-plant adult colonies (Rinkevich 2014). However, for prioritization of species in 341 restoration initiatives based on propagation of sexually produced coral stock (dela Cruz and 342 Harrison 2020), we recommend traits other than growth form to be used for defining species' 343 suitability for restoration, such as the mode of reproduction (large amounts of sexually produced 344 offspring are easier to obtain from broadcast spawning as compared to brooding species; 345 Doropoulos et al., 2019), high early life survivorship, and fecundity (species with higher 346 fecundity can provide larger numbers of sexually produced offspring; Alvarez-Noriega et al., 347 2016). An obstacle for selecting species for restoration based on sexual reproduction is that the 348 knowledge of husbandry is limited for many spawning coral species, and it will always be 349 challenging to obtain high abundances of sexually produced offspring from brooding species 350 (Randall et al., 2020). However, the triage process can be used to highlight where husbandry 351 effort should be directed. For example, Fig. 4 contrasts the best set of species for restoration 352 based on ecological persistence and trait diversity (middle columns in panels a and b); however, 353 this list changes when also considering which of these species are amenable to fragmentation and 354 gardening approaches (last columns). Ideally, coral husbandry and out-planting research should 355 focus on reducing this mismatch (e.g., Baria $\square$ Rodriguez et al., 2019).

357 Our understanding of the species and traits that drive reef functions and services is still 358 emerging, placing severe limitations on our capacity to select foundation species for restoration. 359 Many reviews have dealt with the importance of ecosystem functions and services on coral reefs 360 (Harborne et al., 2006, Brandl et al., 2019; Woodhead et al., 2019), including in the context for 361 reef restoration practices (Hein et al., 2021). However, for corals, the experimental and 362 observational evidence linking species to functions is still limited (Brandl et al., 2019), perhaps 363 because of the long timescales of reef-building. For example, recent restoration work from the 364 Florida Keys achieved large increases in the cover of Acropora cervicornis but little benefit to 
365 broader ecological functions (Ladd et al., 2019). Furthermore, in their blueprint for protecting 366 coral reef functions, Bellwood et al (2019) suggest a hierarchical approach, recognizing that all 367 functions are not equal, and that priority functions are likely to be context specific and should be 368 defined in specific restoration objectives. Selecting species based on functions is therefore likely 369 to vary across systems depending on the specific environment, and the values of the local 370 stakeholders. Our triage approach addresses both these limitations by hedging against loss of 371 range of function by capturing a wide range of morphological and life history traits, while 372 simultaneously enhancing the probability that these traits persist in a range of environments. 373 Given the uncertainty inherent to all restoration efforts, we suggest that better knowledge of 374 functions and a clear vision of the goals of restoration is likely to enhance rather than supersede 375 this triage approach.

377 Restoration efforts should explicitly consider the capacity of species to persist in future 378 environments. An increasingly visible pattern is that there are species that are likely to persist in 379 future predicted environments ('winners') and those that are likely to decline in future 380 environments ('losers') (Adam et al., 2021). Whether to protect the hardy or the vulnerable is a 381 widespread debate throughout conservation biology. For example, when selecting protected 382 areas, the decision to protect areas of imminent threat or resistant areas generating the best 383 returns is highly context-dependent (Sacre et al., 2019). Similarly, whether to select winners or 384 losers for restoration is likely to depend on the severity of the threat to the ecosystem, and the 385 traits and functions that are most critical to ecological integrity. Indeed, a species-oriented focus 386 on restoration is likely to favor rare or depleted species with low persistence, while ecosystem387 based restoration is likely to favor foundation species that are dominant and therefore drive 388 ecosystem functions. The triage approach developed here is specifically designed so that both these viewpoints can be incorporated.

This paper's goal was to develop and present a simple and flexible process for decision making around target species for restoration using real and interpolated data. However, the data and 393 results presented here should not be used for decisions without further consideration, 394 consultation and analysis. For example, a multi-criteria decision-making approach is one 395 pathway (Gouezo et al., 2021). Expert elicitation by coral reef scientists is needed but 
396 inadequate, and this process should also include other stakeholders (managers, tourism

397 operators) and pivotally, First Nations people. Moreover, the value of restoration as a

398 management intervention per se must be evaluated against or complement alternative tools, such

399 as protected areas, fish aggregation devices, and artificial structures, and the outcomes of such

400 assessments vary from one ecosystem function to another (Rogers et al 2015). The ultimate goals

401 of restoration, and particularly the ecosystem functions being targeted, should be based on the

402 scale at which restoration has the greatest impact. Moreover, the success of coral restoration

403 hinges upon addressing local and global actions that facilitate natural coral growth and

404 reproduction, such as regulating climate, overharvesting and land-use.

\section{Authors contributions}

408 All authors conceived the idea during a working group meeting organized by $\mathrm{MJHvO}$ and $\mathrm{KQ}$.

409 JSM and MM developed the idea, gathered data and ran analyses. JSM, MM, KQ and MJHvO

410 wrote the first draft. All authors critically revised drafts and added intellectual content.

\section{Acknowledgements}

414 The workshop was funded by the Australian Research Council Laureate Fellowship 415 FL180100036 to MJHvO. CD and LKB acknowledges the Reef Restoration and Adaptation 416 program. ZR acknowledges Australian Research Council LP160101508.

\section{Conflict of Interest}

420 The authors declare that they have no known competing financial interests or personal 421 relationships that could have appeared to influence the work reported in this paper.

\section{Data availability statement}

425 All data and code are available at https://github.com/jmadinlab/species_choice 


\section{References}

Adam, A.A., Garcia, R.A., Galaiduk, R., Tomlinson, S., Radford, B., Thomas, L., \& Richards, Z.T. (2021). Diminishing potential for tropical reefs to function as coral diversity strongholds under climate change conditions. Diversity \& Distributions, 27, 2245-2261.

Adame, M.F., Teutli, C., Santini, N.S., Caamal, J.P., Zaldívar-Jiménez, A., Hernández, R., \& Herrera-Silveira, J.A. (2014). Root Biomass and Production of Mangroves Surrounding a Karstic Oligotrophic Coastal Lagoon. Wetlands, 34, 479-488.

Álvarez-Noriega, M., Baird, A.H., Dornelas, M., Madin, J.S., Cumbo, V.R., \& Connolly, S.R. (2016). Fecundity and the demographic strategies of coral morphologies. Ecology, 97, 3485-3493.

Anthony, K.R.N., Helmstedt, K.J., Bay, L.K., Fidelman, P., Hussey, K.E., Lundgren, P., Mead, challenge. PLOS ONE, 15, e0236399.

Baddeley, A., Rubak, E., \& Turner, R. (2015). Spatial Point Patterns: Methodology and Applications with R. London: Chapman and Hall/CRC Press.

Baria $\square$ Rodriguez, M.V., dela Cruz, D.W., Dizon, R.M., Yap, H.T., \& Villanueva R.D. (2019).

Bellwood, D.R., Pratchett, M.S., Morrison, T.H., Gurney, G.G., Hughes, T.P., Álvarez-Romero, Performance and cost $\square$ effectiveness of sexually produced Acropora granulosa juveniles compared with asexually generated coral fragments in restoring degraded reef areas. Aquatic Conservation: Marine and Freshwater Ecosystems, 29, 891-900. J.G., Day, J.C., Grantham, R., Grech, A., Hoey, A.S., Jones, G.P., Pandolfi, J.M., Tebbett, S.B., Techera, E., Weeks, R., \& Cumming, G.S. (2019). Coral reef conservation in the Anthropocene: Confronting spatial mismatches and prioritizing functions. Biological Conservation, 236, 604-615.

Boström-Einarsson, L., Babcock, R.C., Bayraktarov, E., Ceccarelli D., Cook, N., Ferse, S.C.A., Hancock, B., Harrison, P., Hein, M., Shaver, E., Smith, A., Suggett, D., Stewart-Sinclair, P.J., Vardi, T., McLeod, I.M. (2020). Coral restoration - A systematic review of current methods, successes, failures and future directions. PLoS ONE, 15,.e0226631.

Brainard, J. (2020). Tasmanian devil reintroduced. Science, 370,268-268. 
Brandl, S.J., Rasher, D.B., Côté, I.M., Casey, J.M., Darling, E.S., Lefcheck, J.S., Duffy, J.E. (2019). Coral reef ecosystem functioning: eight core processes and the role of biodiversity. Front Ecol Environ, 17, 445-454.

Brown, J.H. (1984). On the Relationship between Abundance and Distribution of Species. The American Naturalist, 124, 255-279.

Brudvig, L.A., Mabry, C.M. (2008). Trait-Based Filtering of the Regional Species Pool to Guide Ecology, 16, 290-304.

Ceccarelli, D.M., McLeod, I.M., Boström-Einarsson, L., Bryan, S.E., Chartrand, K.M., Emslie, M.J., Gibbs, M.T., Gonzalez Rivero, M., Hein, M.Y., Heyward, A., Kenyon, T.M., Lewis, considerations for management and implementation. PLOS ONE, 15, e0240846.

Cowman, P.F., Quattrini, A.M., Bridge, T.C.L., Watkins-Colwell, G.J., Fadli, N., Grinblat, M., Roberts, T.E., McFadden, C.S., Miller, D.J., Baird, A.H. (2020). An enhanced targetenrichment bait set for Hexacorallia provides phylogenomic resolution of the staghorn corals (Acroporidae) and close relatives. Molecular Phylogenetics and Evolution, 153, 106944.

Darling, E.S., Alvarez-Filip, L., Oliver, T.A., McClanahan, T.R., Côté, I.M. (2012). Evaluating life-history strategies of reef corals from species traits. Ecology Letters, 15,1378-1386.

De'ath G, Fabricius KE, Sweatman H, Puotinen M (2012) The 27-year decline of coral cover on the Great Barrier Reef and its causes. Proc Natl Acad Sci USA 109:17995-17999

dela Cruz DW, Harrison PL (2020) Enhancing coral recruitment through assisted mass settlement of cultured coral larvae. PLOS ONE 15:e0242847 
species: consequences for the structure and dynamics of forested ecosystems. Frontiers in Ecology and the Environment 3:479-486.

Fredriksen S, Filbee-Dexter K, Norderhaug KM, Steen H, Bodvin T, Coleman MA, Moy F,

Wernberg T (2020) Green gravel: a novel restoration tool to combat kelp forest decline.

Scientific reports 10:3983

Gaitán $\square$ Espitia JD, Hobday AJ (2021) Evolutionary principles and genetic considerations for guiding conservation interventions under climate change. Glob Change Biol 27:475-488

Gallagher RV, Falster DS, Maitner BS, Salguero-Gómez R, Vandvik V, Pearse WD, Schneider FD, Kattge J, Poelen JH, Madin JS, Ankenbrand MJ, Penone C, Feng X, Adams VM,

Ecology \& Evolution 4:294-303

Game ET, Tallis H, Olander L, Alexander SM, Busch J, Cartwright N, Kalies EL, Masuda YJ, Mupepele A-C, Qiu J, Rooney A, Sills E, Sutherland WJ (2018) Cross-discipline evidence principles for sustainability policy. Nat Sustain 1:452-454

Giannini TC, Giulietti AM, Harley RM, Viana PL, Jaffe R, Alves R, Pinto CE, Mota NFO, Caldeira CF, Imperatriz-Fonseca VL, Furtini AE, Siqueira JO (2017) Selecting plant species for practical restoration of degraded lands using a multiple-trait approach. Austral Ecology 42:510-521

Gouezo M, Fabricius K, Harrison P, Golbuu Y, Doropoulos C (2021) Optimizing coral reef

González-Barrios FJ, Álvarez-Filip L (2018) A framework for measuring coral species-specific contribution to reef functioning in the Caribbean. Ecological Indicators 95:877-886

Goreau TF (1963) Calcium carbonate deposition by coralline algae and corals in relation to their roles as reef $\square$ builders. Comparative Biology of Calcified Tissue, Volume 109, Issue1 pp.

514 Graham NAJ, Nash KL (2013) The importance of structural complexity in coral reef ecosystems. $515 \quad$ Coral Reefs 32:315-326

516 Hale SL, Koprowski JL (2018) Ecosystem-level effects of keystone species reintroduction: a 517 literature review: Effects of keystone species reintroduction. Restor Ecol 26:439-445 
Halford A, Cheal AJ, Ryan D, Williams DMcB (2004) Resilience to large-scale disturbance in coral and fish assemblages on the Great Barrier Reef. Ecology 85:1892-1905

Harborne AR, Mumby PJ, Micheli F, Perry CT, Dahlgren CP, Holmes KE, Brumbaugh DR (2006) The Functional Value of Caribbean Coral Reef, Seagrass and Mangrove Habitats to Ecosystem Processes. Advances in Marine Biology. Elsevier, pp 57-189

Hein MY, Vardi T, Shaver EC, Pioch S, Boström-Einarsson L, Ahmed M, Grimsditch G, McLeod IM (2021) Perspectives on the Use of Coral Reef Restoration as a Strategy to Support and Improve Reef Ecosystem Services. Front Mar Sci 8:618303

Hobbs RJ, Hallett LM, Ehrlich PR, Mooney HA (2011) Intervention Ecology: Applying Ecological Science in the Twenty-first Century. BioScience 61:442-450

Hock K, Wolff NH, Ortiz JC, Condie SA, Anthony KRN, Blackwell PG, Mumby PJ (2017) Connectivity and systemic resilience of the Great Barrier Reef. PLoS Biol 15:e2003355

Howlett L, et al. (in review) Adoption of coral propagation and out-planting via the tourism industry to advance site stewardship on the northern Great Barrier Reef.

Hughes TP, Bellwood DR, Connolly SR, Cornell HV, Karlson RH (2014) Double Jeopardy and Global Extinction Risk in Corals and Reef Fishes. Current Biology 24:2946-2951

Hughes TP, Kerry JT, Álvarez-Noriega M, Álvarez-Romero JG, Anderson KD, Baird AH, Babcock RC, Beger M, Bellwood DR, Berkelmans R (2017) Global warming and recurrent mass bleaching of corals. Nature 543:373-377

Hughes, T. P., Connolly, S. R., Keith, S. A. (2013) Geographic ranges of reef corals (Cnidaria: Anthozoa: Scleractinia) in the Indo-Pacific. Ecology 94, 1659

Ladd MC, Burkepile DE, Shantz AA (2019) Near $\square$ term impacts of coral restoration on target species, coral reef community structure, and ecological processes. Restor Ecol 27:11661176

Ladouceur E, Shackelford N (2021) The power of data synthesis to shape the future of the

544 Lamb D (2018) Undertaking large-scale forest restoration to generate ecosystem services:

545 Landscape restoration and ecosystem services. Restor Ecol 26:657-666

546 Lott MJ, Wright BR, Kemp LF, Johnson RN, Hogg CJ (2020) Genetic Management of Captive 547 and Reintroduced Bilby Populations. J Wildl Manage 84:20-32 
Madin JS, Anderson KD, Andreasen MH, Bridge TCL, Cairns SD, Connolly SR, Darling ES, Diaz M, Falster DS, Franklin EC, Gates RD, Hoogenboom MO, Huang D, Keith SA, Kosnik MA, Kuo C-Y, Lough JM, Lovelock CE, Luiz O, Martinelli J, et al. (2016) The Coral Trait Database, a curated database of trait information for coral species from the global oceans. Scientific Data 3:160017

Marshall N, Marshall P, Curnock M, Pert P, Smith A, Visperas B (2019) Identifying indicators of aesthetics in the Great Barrier Reef for the purposes of management. PLoS ONE 14:e0210196

McAfee D, Costanza R, Connell SD (2021) Valuing marine restoration beyond the 'too small and too expensive.' Trends in Ecology \& Evolution 36:968-971

McWilliam M, Hoogenboom MO, Baird AH, Kuo C-Y, Madin JS, Hughes TP (2018) Biogeographical disparity in the functional diversity and redundancy of corals. Proceedings of the National Academy of Sciences 115:3084-3089

Meli P, Martínez-Ramos M, Rey-Benayas JM (2013) Selecting Species for Passive and Active Riparian Restoration in Southern Mexico: Selecting Species for Riparian Restoration. Restor Ecol 21:163-165

Orth RJ, Lefcheck JS, McGlathery KS, Aoki L, Luckenbach MW, Moore KA, Oreska MPJ, Snyder R, Wilcox DJ, Lusk B (2020) Restoration of seagrass habitat leads to rapid

Randall CJ, Negri AP, Quigley KM, Foster T, Ricardo GF, Webster NS, Bay LK, Harrison PL,

Babcock RC, Heyward AJ (2020) Sexual production of corals for reef restoration in the Anthropocene. Mar Ecol Prog Ser 635:203-232 recovery of coastal ecosystem services. Science Advances 6:eabc6434

R Core Team (2021). R: A language and environment for statistical computing. R Foundation for Statistical Computing, Vienna, Austria. URL https://www.R-project.org/.

Renka RJ, Gebhardt A, Eglen S, Zuyev S, White D (2020) tripack: Triangulation of Irregularly Spaced Data. R package version 1.3-9.1

Rinkevich B (2014) Rebuilding coral reefs: does active reef restoration lead to sustainable reefs? Current Opinion in Environmental Sustainability 7:28-36 
Ripple WJ, Estes JA, Beschta RL, Wilmers CC, Ritchie EG, Hebblewhite M, Berger J,

Elmhagen B, Letnic M, Nelson MP, Schmitz OJ, Smith DW, Wallach AD, Wirsing AJ $343: 1241484$

Rogers A, Harborne AR, Brown CJ, Bozec Y-M, Castro C, Chollett I, Hock K, Knowland CA, Marshell A, Ortiz JC, Razak T, Roff G, Samper-Villarreal J, Saunders MI, Wolff NH,

Sacre E, Bode M, Weeks R, Pressey RL (2019) The context dependence of frontier versus Mumby PJ (2015) Anticipative management for coral reef ecosystem services in the 21st wilderness conservation priorities. Conservation Letters 12:

Staude IR, Navarro LM, Pereira HM (2020) Range size predicts the risk of local extinction from habitat loss. Global Ecol Biogeogr 29:16-25

Stearns, S. (1992). The Evolution of Life Histories. Oxford ; New York: Oxford University Press.

Strassburg BBN, Iribarrem A, Beyer HL, Cordeiro CL, Crouzeilles R, Jakovac CC, Braga Junqueira A, Lacerda E, Latawiec AE, Balmford A, Brooks TM, Butchart SHM, Chazdon

Suding KN, Gross KL, Houseman GR (2004) Alternative states and positive feedbacks in

Suggett DJ, Camp EF, Edmondson J, Boström $\square$ Einarsson L, Ramler V, Lohr K, Patterson JT (2019) Optimizing return $\square$ on $\square$ effort for coral nursery and outplanting practices to aid restoration of the Great Barrier Reef. Restor Ecol 27:683-693

Swain TD, Vega $\square$ Perkins JB, Oestreich WK, Triebold C, DuBois E, Henss J, Baird A, Siple M, Backman V, Marcelino L (2016) Coral bleaching response index: a new tool to standardize and compare susceptibility to thermal bleaching. Glob Change Biol 22:2475-2488

Vanderklift MA, Doropoulos C, Gorman D, Leal I, Minne AJP, Statton J, Steven ADL, Wernberg T (2020) Using Propagules to Restore Coastal Marine Ecosystems. Front Mar Sci 7:724

Veron, J. E. N. (2000) Corals of the World. Australian Institute of Marine Science and CCR Qld Pty Ltd. 
610 Villéger S, Mason NWH, Mouillot D (2008) New multidimensional functional diversity indices

611 for a multifaceted framework in functional ecology. Ecology 89:2290-2301

612 Westoby M, Falster DS, Moles AT, Vesk PA, Wright IJ (2002) Plant Ecological Strategies:

613 Some Leading Dimensions of Variation Between Species. Annual Review of Ecology and

$614 \quad$ Systematics 33:125-159

615 Woodhead, A.J., Hicks, C.C., Norström, A.V., Williams, G.J., Graham, N.A.J. (2019) Coral reef

616 ecosystem services in the Anthropocene. Funct Ecol, 1365-2435.13331.

617 Zawada, K.J.A., Dornelas, M., Madin, J.S. (2019) Quantifying coral morphology. Coral Reefs

$618 \quad 38,1281-1292$. 
619 Figure 1. Selecting sets of species for restoration with a two-part triage approach. The orange 620 panel shows ecological functions that are important or threatened. If mechanistic linkages 621 between life history traits and functions are established, then triage could focus on specific high622 priority functions (left blue panel). Alternatively, a bet hedging approach that maximizes the 623 diversity of functional and life history traits increases the likelihood that multiple functions are 624 performed across a range of environments (right blue panel). Next, the species supporting 625 functions are narrowed down further to include only those with characteristics that enhance or 626 diminish their chances of persisting (green panel), resulting in different lists of species (yellow 627 panel).

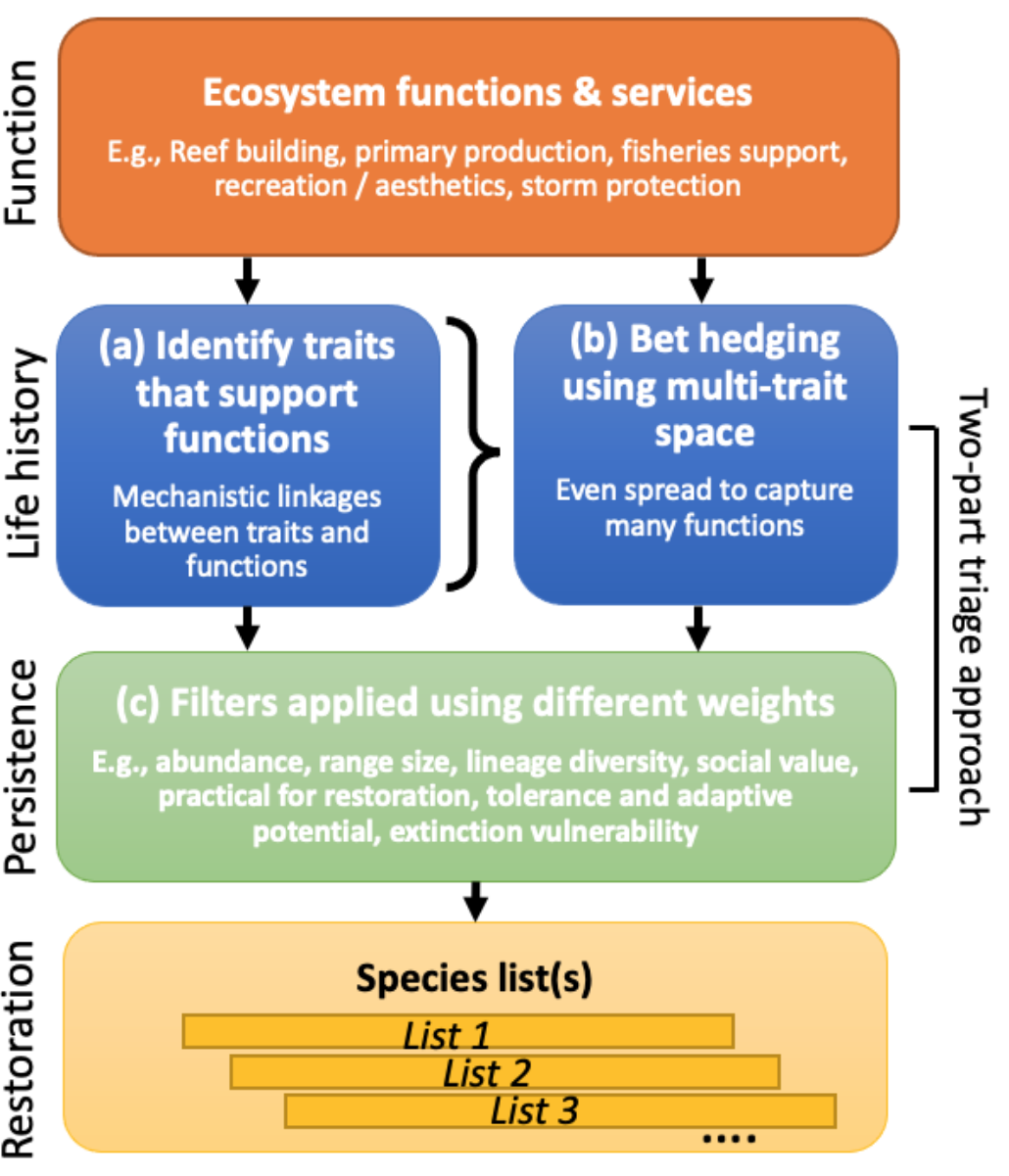


629 Figure 2. Phenotypic trait space is represented as the first two principal component axes for 396 630 east coast Australia coral species. (a) The trait loadings: growth rate (GR), corallite width (CW), 631 rugosity/branch spacing (R), surface area per unit volume (SAV), colony height (CH), maximum 632 colony size/diameter (MCS), and skeletal density (SD). Red vectors are Goreau's (1963) 633 categories of essential reef builders. (b) An overlay illustrating where several functions 634 approximately lie in trait space. Some functions require species broadly across the space, 635 whereas others only a limited region of the space. (c) Selections of evenly spread species $(\mathrm{n}=20)$ 636 calculated using nearest neighbor distances (points) and Voronoi cell areas (crosses and dashed 637 line). (d) Selections based on ecological persistence characteristics only (crosses and grey 638 shading) and then with the addition of trait diversity weighting (points) demonstrating the two639 part triage. (e) The 15 common Lord Howe Island species (crosses) and 15 species selected using 640 the triage approach (points). (f) The 39 Coral Nurture Program species (crosses) and 39 species 641 selected using the triage approach (points). The red arrow shows an outlier species, Galaxea 642 fascicularis. 
bioRxiv preprint doi: https://doi.org/10.1101/2021.11.03.467181; this version posted November 21, 2021. The copyright holder for this preprint (which was not certified by peer review) is the author/funder, who has granted bioRxiv a license to display the preprint in perpetuity. It is made available under aCC-BY-NC-ND 4.0 International license.

(a)

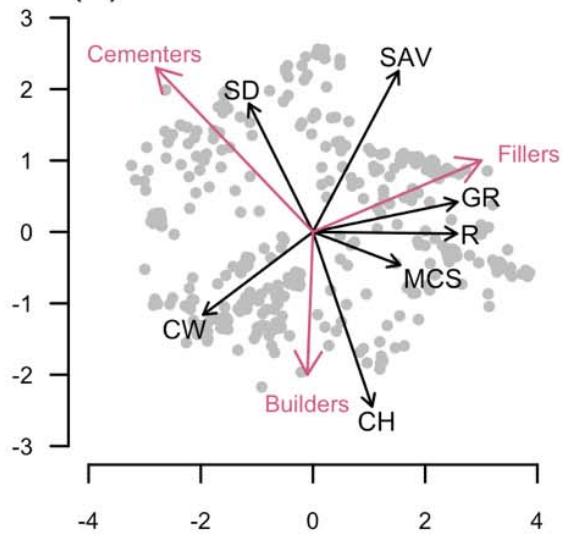

(c)

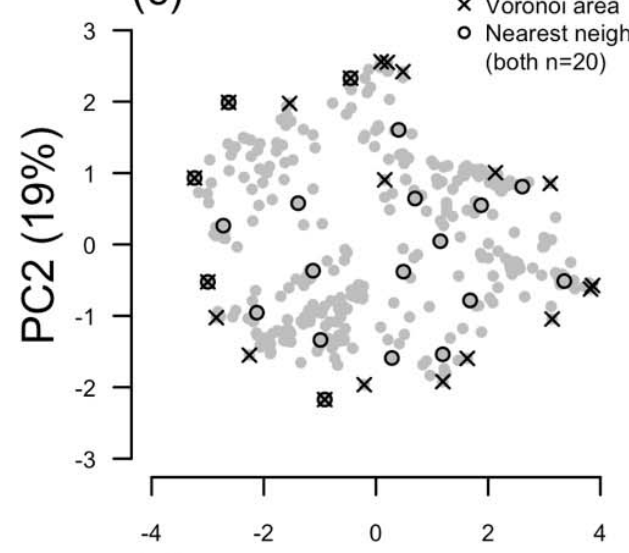

(e)

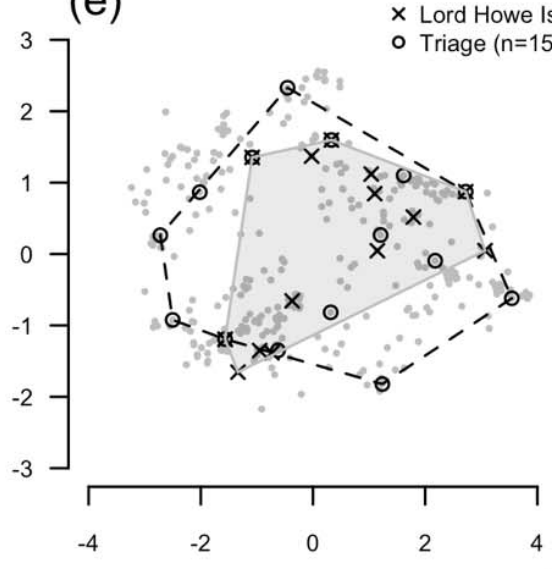

(b)

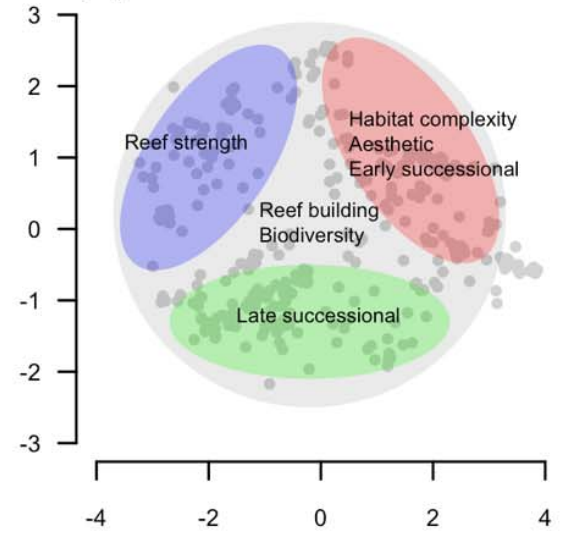

(d)

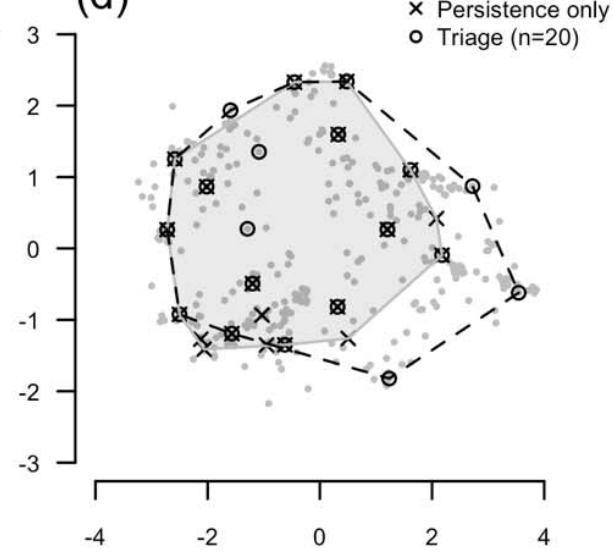

(f)

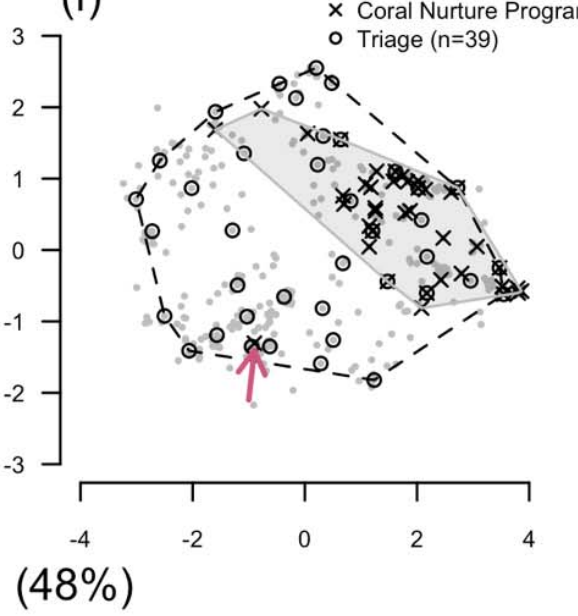

643

PC1 (48\%) 
644 Figure 3. (a) Proportion occupancy and (b) redundancy in trait space as a function of number of 645 species n using a 5 by 5 cell grid (inset in panel a). Regions of high, medium and low marginal 646 returns delineated with dotted vertical lines. Included are symbols that show trait diversity and 647 redundancy for common species at Lord Howe Island $(n=15)$ and for the Coral Nurture Program 648 (n=39). The grey shaded region shows 95\% CIs for randomized species selection.

(a)

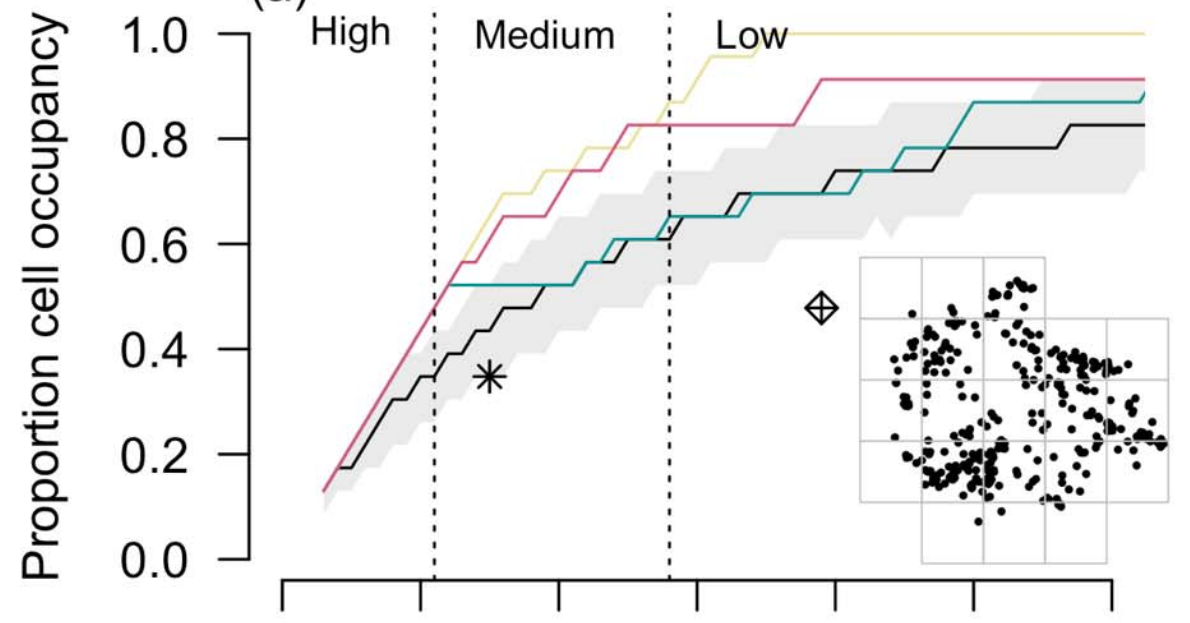

(b)

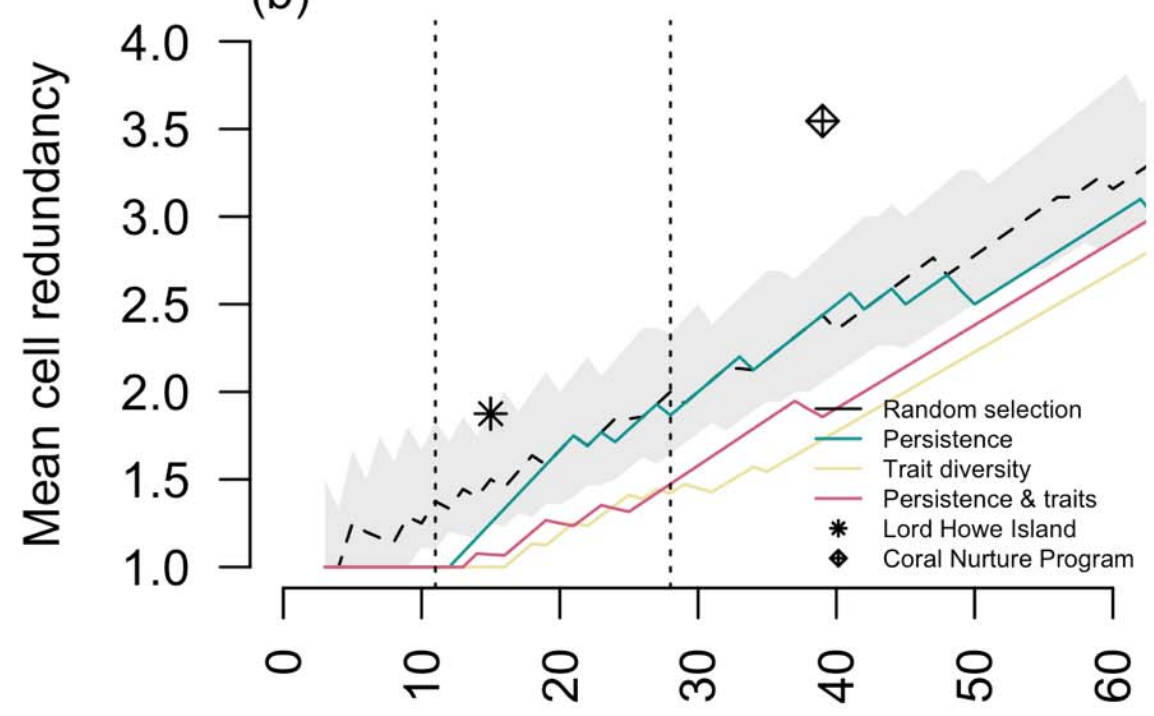

\section{Number of species}


650 Figure 4. Species selected $(n=20)$ at different stages of the triage process when focusing on (a) 651 ecological persistent species in terms of range size and local abundance, bleaching resistance, 652 and suitability for restoration, and (b) species that have a large range size and are ecologically 653 abundant, vulnerable to bleaching, and suitable for restoration. Values (and heat colors) 654 correspond with a species triage score at successive stages. Asterisks (*) denote species found at 655 Lord Howe Island; pluses (+) denote Coral Nurture Program species from Howlett et al. (in 656 review). 


\begin{tabular}{|c|c|c|c|c|c|c|c|}
\hline (a) & 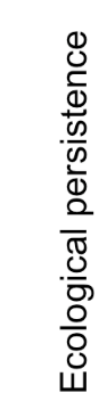 & 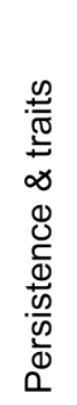 & 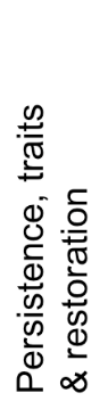 & (b) & 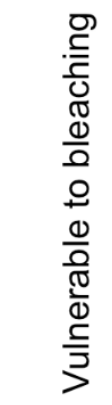 & 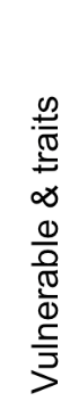 & 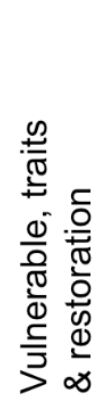 \\
\hline & $L$ & 1 & $\downarrow$ & & $L$ & $\perp$ & $\downarrow$ \\
\hline Species 115+ & $\square$ & & 0.3 & Species 22 & $\square$ & & 0.17 \\
\hline Species $49^{*}$ & - & & 0.3 & Species $244^{*}$ & - & & 0.16 \\
\hline Species 17+ & - & & 0.3 & Species 69 & - & & 0.11 \\
\hline Species 9 & - & & 0.25 & Species 114 & - & & 0.1 \\
\hline Species 60+ & -1 & 0.66 & 0.38 & Species 42 & - & & 0.09 \\
\hline Species 128 & -1 & 0.45 & & Species 174 & - & 0.32 & \\
\hline Species $322^{*}$ & - & 0.39 & & Species 171 & - & 0.21 & 0.13 \\
\hline Species $59^{*}$ & - & 0.34 & 0.31 & Species $17^{*}$ & - & 0.16 & 0.19 \\
\hline Species 156 & - & 0.3 & 0.28 & Species 319 & & 0.15 & \\
\hline Species 18 & - & 0.29 & & Species $221^{*}$ & - & 0.13 & 0.15 \\
\hline Species $8^{*}$ & 0.9 & 0.33 & 0.38 & Species 258 & 0.47 & 0.24 & 0.16 \\
\hline Species 334 & 0.86 & 0.63 & & Species 47 & 0.45 & 0.25 & 0.21 \\
\hline Species $355^{*}$ & 0.76 & 0.39 & 0.36 & Species $105^{*}$ & 0.44 & 0.13 & \\
\hline Species 44 & 0.74 & 0.38 & 0.35 & Species 107 & 0.41 & 0.14 & 0.15 \\
\hline Species 67 & 0.72 & & 0.31 & Species 77 & 0.4 & 0.12 & \\
\hline Species 82 & 0.72 & 0.46 & 0.42 & Species 238* & 0.4 & 0.14 & 0.15 \\
\hline Species 23 & 0.72 & 0.51 & & Species $100^{*}$ & 0.39 & 0.12 & 0.23 \\
\hline Species 219+ & 0.71 & 0.45 & & Species $260^{*}$ & 0.39 & 0.11 & 0.23 \\
\hline Species 346 & 0.7 & 0.44 & 0.51 & Species 194 & 0.38 & 0.15 & 0.14 \\
\hline Species 96 & 0.69 & 0.31 & 0.35 & Species $125^{\star}$ & 0.36 & & \\
\hline Species 182 & 0.68 & 0.32 & 0.3 & Species $234^{*}$ & 0.36 & 0.13 & 0.26 \\
\hline Species 196 & 0.68 & 0.45 & 0.31 & Species 310 & 0.36 & 0.13 & \\
\hline Species 58 & 0.68 & 0.32 & & Species 130 & 0.36 & 0.17 & 0.11 \\
\hline Species 92+ & 0.67 & 0.43 & 0.48 & Species 259 & 0.35 & & \\
\hline Species 222 & 0.67 & & 0.56 & Species 229 & 0.35 & 0.13 & 0.11 \\
\hline Species $65^{*}$ & 0.67 & & & Species 68 & 0.34 & & \\
\hline Species 287 & 0.67 & & & Species 190 & 0.34 & 0.16 & 0.17 \\
\hline Species 120 & 0.67 & 0.35 & 0.25 & Species 18 & 0.34 & 0.25 & 0.13 \\
\hline Species 147 & 0.67 & & & Species 62 & 0.33 & & \\
\hline Species 224 & 0.67 & & 0.56 & Species 256 & 0.33 & & \\
\hline
\end{tabular}

